\title{
Engaged but exhausted: Work-related wellbeing profiles of South African employees
}

\author{
Leoni van der Vaart · Leon T. de Beer
}

\begin{abstract}
Organizations and colleagues alike benefit from dedicated employees who are immersed in their work and energetically pursue their tasks. Unfortunately, this may come at a price for employees who may burn out. Organizations are, therefore, confronted with a responsibility to assist employees in striking a balance between eagerly engaging in their tasks and taking care of their wellbeing. Before designing and implementing interventions, it is valuable to identify how engagement and burnout components cluster within individuals and whether these different combinations have different implications for employees. The study aimed to explore whether burnout and work engagement combine within individuals to form different burnout-engagement profiles. The study also aimed to examine the implications of different profiles for employees' psychological distress, affective commitment, and turnover intention. Among 1048 South African employees, latent profile analysis highlighted five distinct burnout-engagement profiles: Burned-out, Risky, Moderately balanced, Stars, and Workaholics. The Burned-out reported higher levels of psychological distress than the Risky. Still, both reported higher levels than the Moderately balanced, who also reported higher levels of psychological distress than the Stars. The Burned out and the Workaholics reported equal levels of psychological distress. The Stars reported the highest levels of affective commitment, followed by the Workaholics, the Moderately balanced, and the Risky, with the lowest levels reported by the Burned-out. The Burned-out reported the highest levels of turnover intention, followed by the Risky, the Workaholics, and the Moderately balanced, with the lowest levels reported by the Stars. Limitations, recommendations for future research and practical implications are discussed.
\end{abstract}

Keywords: burnout; work engagement; latent profile analysis; wellbeing profiles; employee wellbeing

\section{Introduction}

There is no question that COVID-19 and the associated lockdowns have accelerated changes within organizations, sectors, and societies (Giorgi et al., 2020). For example, organizations were forced to implement work-from-home practices to remain sustainable during 'hard lockdown'. While many of these changes were beneficial for employees, remote working also introduced challenges. Employees reported greater autonomy and flexibility, but at the same time, they experienced a lack of equipment and other resources, increased parenting duties, and a lack of effective communication and meaningful connections (De Klerk et al., 2021; Koekemoer et al., 2021). Therefore, the pandemic (and remote working arrangements) comes with a trade-off by increasing employee motivation and engagement and decreasing employee job-related wellbeing such as burnout. As many companies indicated that they wish to continue with

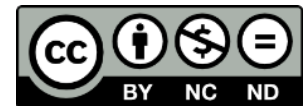

Copyright belongs to the author(s) www.internationaljournalofwellbeing.org 
remote work (or to some extent), organizations are confronted with a responsibility to assist employees in striking a balance between eagerly engaging in their tasks and taking care of their wellbeing even after the pandemic. Consequently, employers need to understand the interplay of work engagement and burnout and the consequence of this interplay to design effective interventions.

Burnout research has been ongoing for half a century, and the term has resurged in the public sphere due to attention that the World Health Organization's (WHO) changes to the ICD11 for 2022 has commanded (WHO, 2019). Similarly, work engagement research has been around since the 1990s (Bakker et al., 2014). However, most research on engagement and burnout took a variable-centered approach to study these constructs, their antecedents, and their outcomes instead of a person-centered approach (Abós et al., 2019; Moeller et al., 2018). Person-centered approaches reject the notion of homogeneity, implied by variable-centered approaches, assuming that the heterogeneous population consists of several homogenous subgroups (or sub-populations) identified through their differential responses to the variables under investigation. Such an approach acknowledges that variables combine within individuals (to form sub-groups), and this combination has implications for individuals' affect, behavior, and cognition (Morin et al., 2018).

As a developing area of research, person-centered studies (on burnout and engagement) started to emerge more recently, also in the work context (see Abós et al., 2019; Innanen et al., 2014; Moeller et al., 2018; Samela-Aro et al., 2019). Although these studies are valuable, they are limited in number and scope, and our study has at least three advancements. First, none of these studies has used the theoretical facets of burnout proposed by Schaufeli et al. (2020). As burnout research is nuanced (De Beer, 2021), theoretical developments are imperative, and measuring instruments should keep up with such developments. Consequently, Schaufeli and colleagues developed a new instrument using both inductive and deductive approaches. The Burnout Assessment Tool (BAT) is presented as a more contemporary, updated and psychometrically sound scale compared to other existing burnout instruments (see Schaufeli et al., 2020 for an overview of the development of the scale and critique against other conceptualizations and measurements of burnout). Second, these studies did not investigate the total and specific levels of engagement and burnout simultaneously, a second-order total score with the specific firstorder components. Research demonstrated that employees could, for example, experience burnout holistically (as a single dimension) but also that the different components thereof remain important (Gillet et al., 2021). Combining these two possibilities (total vs specific) suggests that employees can present a global burnout experience (as a total score). The specific levels of exhaustion, cognitive and emotional impairment, and mental distance may also provide unique insights.

Consequently, in line with burnout's definition as a syndrome, a second-order factor score indicated by the scale's items, mediated by the four specific components, is considered the most theoretically sound operationalization. Similarly, work engagement is most often modelled (except by Innanen et al., 2014) as unidimensional. In the current study, it will also be modelled as a second-order model juxtaposed to BAT-assessed burnout. Third, all these studies were conducted in WEIRD (i.e., Western, Educated, Industrialized, Rich, and Democratic) contexts. South Africa, as a developing country, differs significantly from WEIRD countries based on these indicators. Previous studies (De Beer et al., 2020; Schaufeli, 2017a) indicated that engagement and burnout levels could differ depending on the country in which it is measured, potentially influencing the emergence and prevalence of different burnout-engagement profiles. 
The current study aimed to extend to the scientific conversation on burnout-engagement profiles by exploring how BAT-assessed burnout (see Schaufeli et al., 2020) and work engagement cluster within individuals (from a non-WEIRD context) to form different burnoutengagement profiles. The study also aimed to examine the implications of the different profiles for employee outcomes (i.e., psychological distress, affective organizational commitment, and turnover intention). These outcomes are often associated with engagement and burnout, and they have important implications (i.e., performance and turnover) for organizations. The study also provides valuable information that organizations can use to tailor their interventions for these different groups by pursuing these aims.

\subsection{Burnout-engagement profiles: Two sides of the same coin}

Employee work engagement is defined as a "persistent and pervasive affective-cognitive state that is not focused on any particular object, event, individual, or behavior" (Schaufeli \& Bakker, 2004, p. 295). It is characterized by vigor (i.e., having high levels of energy and mental resilience), dedication (i.e., feeling inspired, proud, and enthusiastic), and absorption (i.e., being engrossed in one's work) (Decuypere \& Schaufeli, 2020; Schaufeli \& Bakker, 2004). Burnout is defined as "a work-related state of exhaustion that occurs among employees, which is characterized by extreme tiredness, reduced ability to regulate cognitive and emotional processes, and mental distancing" (Schaufeli et al., 2020, p. 4). BAT-assessed burnout adds two additional components (cognitive- and emotional impairment; the reduced functional capacity to manage cognitions/emotions) but does not include the professional (in)efficacy component as it was not a major component in the development of the BAT. The omission of professional (in)efficacy is in line with research that provided evidence questioning the role of professional (in)efficacy in the burnout syndrome (e.g., De Beer \& Bianchi, 2019; Schaufeli \& Salanova, 2007).

Burnout and engagement have been posited to be located on different ends of two continua (i.e., the pleasure-displeasure continuum and the high activation-low activation continuum) of the circumplex model of subjective wellbeing. Whereas burnout is depicted as an unpleasantlow activation state, engagement is depicted as a pleasant-high activation state (Bakker \& Oerlemans, 2011; Innanen et al., 2014; Schaufeli, 2017b). Despite the presence of these states on opposites of the continua, several person-centered studies (Abós et al., 2019; Innanen et al., 2014; Moeller et al., 2018; Samela-Aro et al., 2019) illustrated that employees could experience the two states simultaneously. Previous studies supported this and showed that engagement and burnout components could combine to form between two (Innanen et al., 2014; Samela-Aro et al., 2019) and five (Abós et al., 2019; Moeller et al., 2018) profiles. More specifically, past research illustrated that burnout and engagement cluster to form quantitatively and qualitatively different profiles: high burnout-high engagement, moderate burnout-moderate engagement, low burnout-low engagement, high burnout-low engagement, and low burnout-high engagement profiles.

Lacking prior guidance from research, in which the total scores and specific components of burnout and engagement were specifically investigated, a more open hypothesis is framed in which the number of profiles is considered but not the structure (that will best reflect employees' wellbeing configurations) thereof.

\subsection{Psychological distress, affective organizational commitment, and turnover intention as correlates of profile membership}

The study's second aim was to investigate if the identified profiles differ in psychological distress, affective commitment, and turnover intention. Psychological distress refers to non- 
specific psychological and psychosomatic complaints (Schaufeli et al., 2020; De Beer, 2021). Affective commitment refers to the emotional connection an employee has with the organization. Affectively committed employees identify with the organization and remain in it because they want to (Allen \& Meyer, 1996). Lastly, turnover intention refers to an employee's desire or plan to leave the organization (Tett \& Meyer, 1993).

According to the health impairment process of the job demands-resources (JD-R) theory, burned-out employees experience a depletion of their energetic resources and consequently develop health-related problems which undermine their functioning (Bakker \& Demerouti, 2017). Therefore, burnout initiates a process that results in impaired psychological functioning (i.e., psychological distress). Burned-out individuals can also not connect emotionally with the organization because they no longer identify with the organization (Knoll et al., 2019; Meyer et al., 2006). As part of the coping process, these individuals may want to escape their dire situation and develop a desire to leave the organization. Previous variable-centered studies confirmed the positive relationship between burnout and psychological distress (De Beer, 2021) and turnover intention (Wang et al., 2020) and the negative relationship between burnout and affective commitment (Sarisik et al., 2019).

Engaged employees with a 'want to' orientation experience improved functioning through a motivational process of the JD-R model (Bakker \& Demerouti, 2017). Therefore, engaged employees function well psychologically. They are emotionally invested in (and identify with) the organization and wish to remain in it. Previous variable-centered studies have supported the negative relationship between engagement and psychological distress (Shimazu et al., 2018; Van Mol et al., 2018) and turnover intention (Coetzee \& Van Dyk, 2018), and the positive relationship between engagement and affective commitment (Guo et al., 2020).

In line with findings from variable-centered approaches, person-centered studies reported more favorable associations between profiles with low(er) levels of burnout and high(er) levels of engagement and affective outcomes (Abós et al., 2019; Innanen et al., 2014; Moeller et al., 2018). Similarly, these studies also reported more favorable associations between profiles with low(er) levels of burnout and high(er) levels of engagement and cognitive outcomes (Abós et al., 2019; Moeller et al., 2018). These findings illustrate engagement's potential to offset the negative consequences of burnout. One exception to this trend is the tendency for profiles with both high burnout and engagement levels to report mixed associations with outcomes. For example, individuals in the engaged but exhausted profiles reported both positive and negative affective experiences but still reported high levels of turnover intention (Moeller et al., 2018). These findings illustrate that positive outcomes (e.g., commitment) may result from high engagement levels, but this comes at a cost (i.e., psychological distress and wanting to leave).

\subsection{Hypotheses}

Hypothesis 1. Five burnout-engagement profiles can be identified.

Hypothesis 2a. Profiles with high(er) levels of burnout and low(er) levels of engagement may be less adaptive profiles with higher levels of psychological distress compared to those with low(er) levels of burnout and high(er) levels of engagement. Those with high levels of both burnout and engagement will also report high levels of psychological distress.

Hypothesis $2 b$. Profiles with high(er) levels of burnout and low(er) levels of engagement may be less adaptive profiles with lower levels of affective commitment compared to those with low(er) levels of burnout and high(er) levels of engagement. Those with high levels of both burnout and engagement will also have high levels of affective commitment. 
Hypothesis 2c. Profiles with high(er) levels of burnout and low(er) levels of engagement may be less adaptive profiles with higher levels of turnover intentions compared to those with low(er) levels of burnout and high(er) levels of engagement. Those with high levels of both burnout and engagement will also have high levels of turnover intentions.

\section{Method}

\subsection{Participants}

A purposive sample of participants $(n=1048)$ was used from the Burnout Assessment Tool project. Specifically, participants had to be at least 18 years of age and employed in South Africa at the time of the study. Data were collected with an online survey distributed on social media and to immediate networks via e-mail. A national newspaper also ran an article on burnout which included a link to the online survey. The mean age of participants was $40.80(\mathrm{SD}=11.20)$. More than half of the participants were females (54.50\%). Participants' educational levels ranged from secondary (46.00\%) to post-secondary school qualifications $(54.00 \%)$. The most commonly occurring ethnic ${ }^{1}$ category was white $(37.10 \%)$, followed by African $(36.10 \%)$, Indian $(12.10 \%)$, Coloured (12.10\%), and Asian (3.10\%) employees. The relevant institutional research ethics committee granted ethics approval for the project which complied with ethical guidelines such as voluntary participation, informed consent, and confidentiality (Ref: NWU-00558-17-A4).

\subsection{Measures}

Burnout was measured with the core version of the Burnout Assessment Tool (BAT-23) (Schaufeli et al., 2020). The BAT comprises 23 items measured on a 5-point Likert scale ranging from 1 ('strongly disagree') to 5 ('strongly agree'). The BAT measures burnout as a syndrome in line with its definitional operationalization and comprises exhaustion (8 items; e.g., 'When I get up in the morning, I lack the energy to start a new day at work'), mental distance ( 5 items; e.g., 'I feel indifferent about my job'), cognitive impairment (5 items; e.g., 'When I'm working, I have trouble concentrating'), and emotional impairment (5 items; e.g., 'At work, I feel unable to control my emotions').

Work engagement was measured with the short version of the Utrecht Work Engagement Scale (UWES-9) (Schaufeli et al., 2006). The UWES-9 contains a total of nine items measured on a 7point frequency scale ranging from 0 ('never') to 6 ('always'). The items are divided equally between vigor (e.g., 'I get carried away when I am working'), dedication (e.g., 'I am enthusiastic about my job'), and absorption (e.g., 'I am immersed in my work').

Psychological distress was measured as a single scale consisting of both psychological and psychosomatic complaints, with the secondary symptoms scale of the BAT (Schaufeli et al., 2020). It comprises 10 items divided equally between psychological (e.g., 'I feel tense and stressed') and psychosomatic complaints (e.g., 'I often get sick'). These items are measured on a 5-point frequency scale ranging from 1 ('Never') to 5 ('Always').

Turnover intention was measured with three items developed by Hellgren et al. (1997). The items (e.g., 'I feel that I could leave this job') are measured on a 5-point Likert scale ranging from 1 ('strongly disagree') to 5 ('strongly agree').

Affective organizational commitment was measured with five items from the Affective Commitment Scale (Allen \& Meyer, 1990). The items are measured on a 5-point frequency scale ranging from 1 ('Never') to 5 ('Always').

\footnotetext{
${ }^{1}$ Designations are used in line with the exact terminology of the Employment Equity Act, 55 of 1998 for designated and non-designated groups. No offense is intended.
} 


\subsection{Analysis plan}

Mplus 8.6 (Muthén \& Muthén, 1998-2021) was used for data analyses. Confirmatory factor analysis (CFA) was performed using the robust version of the maximum likelihood (MLR) estimator. The MLR estimator is preferred because of its ability to perform well with the potential of a skewed distribution in the data. We assessed model fit based on the recommendations of Kline (2016): CFI and TLI $\geq .90$; RMSEA and SRMR $\leq .08$. The reliabilities of the scales were calculated using the McDonald's omega reliability coefficient $(\omega)$. Latent profile analysis (LPA) was performed on the factor scores exported from the preliminary measurement models, a practice that has become more common in recent applications of mixture models (Meyer \& Morin, 2016). LPA is a model-based approach that clusters individuals or cases into groups (latent profiles) based on their responses to observed continuous variables (Muthén \& Muthén, 2000). Being model-based, formal statistical procedures are used to determine the optimal number of profiles (Tofighi \& Enders, 2008; Wang \& Wang, 2020).

Deciding on the optimal number of profiles firstly depends on several information criteria: Akaike information criterion (AIC), Bayesian information criterion (BIC) and sample size adjusted BIC (ABIC). The decision secondly depends on whether there are significant differences between the $\mathrm{k}$ and $\mathrm{k}-1$ models. These differences are indicated by $p$-values associated with the Lo-Mendell-Rubin likelihood ratio (LMR) test, the adjusted Lo-Mendell-Rubin likelihood ratio (ALMR) test, and the bootstrap likelihood ratio (BLRT) test. If these $p$-values are significant, the model with fewer profiles is rejected in favor of the model with more profiles (Tofighi \& Enders, 2008; Wang \& Wang, 2020). Simulation studies demonstrated that the BIC and BLRT perform better (Nylund et al., 2007; Tein et al., 2013) and was used in the current research to inform decision-making. Once the number of profiles has been decided on, class classification is examined to determine the reliability with which individuals were assigned. Two criteria are used for this purpose: estimated posterior class-membership probability and the entropy value. For the former, Nagin (2005) recommended values of above .70, and for the latter, Clark (2010) recommended values of $>.80$. It is also recommended that the profile sizes do not become too small (e.g., proportionally, $<1.0 \%$ and/or numerically $n<25$ ) (Lubke \& Neale, 2006).

Finally, we used the Bolck-Croon-Hagenaars (BCH) method (see Bakk \& Vermunt, 2016 for a detailed description) to compare the levels of psychological distress, commitment, and turnover intention across the profiles. The robust $\mathrm{BCH}$ method was preferred as the covariates were continuous data (Asparouhov \& Muthén, 2015).

\section{Results}

\subsection{Confirmatory factor analysis for the profile variables}

The measurement model entailed specifying second-order models for engagement (with its three lower order factors) and burnout (with its four lower order factors). This is in line with the recent validation studies of BAT-assessed burnout that followed a theoretical approach to the modeling of burnout as a syndrome, i.e., global score indicated by the items but mediated by the first-order components (see De Beer, 2021; Vinueza-Solórzano et al., 2021). The model yielded an acceptable fit to the data $\left(\mathrm{SB}-\chi^{2}=1735.61, p<.001 ; \mathrm{d} f=456 ; \mathrm{CFI}=.90 ; \mathrm{TLI}=.89\right.$; RMSEA $=.05[.049, .054], p=.131 ;$ SRMR $=.07)$ and no data-driven model modifications were done posthoc. The reliability coefficients for the respective higher and lower order factors were acceptable: engagement $(\omega=.90)$, dedication $(\omega=.83)$, absorption $(\omega=.68)$, vigor $(\omega=.79)$, 
burnout $(\omega=.94)$, exhaustion $(\omega=.91)$, mental distance $(\omega=.81)$, cognitive impairment $(\omega=.90)$, and emotional impairment $(\omega=.86)$.

\subsection{Latent profile analysis}

The optimal number of classes was determined by estimating six models with increasing numbers of latent classes and comparing the fit statistics of these models. Table 1 shows the fit indices for the models.

Table 1. Comparison of LPA models

\begin{tabular}{|c|c|c|c|c|c|c|c|c|c|c|c|}
\hline Model & $\begin{array}{l}\text { Log } \\
\text { likeli- } \\
\text { hood }\end{array}$ & $\# \mathbf{f p}$ & Scaling & AIC & BIC & ABIC & $\begin{array}{l}\text { LMR } \\
\text { LR } \\
\text { test } p\end{array}$ & $\begin{array}{l}\text { ALMR } \\
\text { LR test } \\
p\end{array}$ & $\begin{array}{l}\text { BLRT } \\
p\end{array}$ & Entropy & $\begin{array}{l}\text { Smallest } \\
\text { class } \\
\text { proportion }\end{array}$ \\
\hline 1-pro & -105 & 18 & 1.07 & 21192.82 & 21282.01 & 21224.84 & - & - & - & - & - \\
\hline 2-profiles & -8014.68 & 28 & 1.52 & 16085.36 & 16224.09 & 16135.16 & 0.00 & 0.00 & 0.00 & 0.93 & 39. \\
\hline 3-profiles & -6990.83 & 38 & 1.79 & 14057.66 & 14245.94 & 14125.24 & 0.06 & 0.06 & 0.00 & 0.93 & $16.80 \%$ \\
\hline 4-profiles & -6171.78 & 48 & 1.73 & 12439.56 & 12677.38 & 12524.93 & 0.02 & 0.02 & 0.00 & 0.95 & $7.70 \%$ \\
\hline 5-profiles & -5818.49 & 58 & 1.83 & 11752.97 & 12040.34 & 11856.12 & 0.08 & 0.08 & 0.00 & 0.95 & $4.40 \%$ \\
\hline 6-profiles & -5303.27 & 68 & 2.17 & 10742.54 & 11079.46 & 10863.48 & 0.45 & 0.45 & 0.00 & 0.94 & $4.10 \%$ \\
\hline
\end{tabular}

Notes. \#fp = number of free parameters; AIC = Akaike information criterion; BIC = Bayesian information criterion; $\mathrm{ABIC}=$ sample size adjusted BIC; LMR $=p$ value associated with the Lo-Mendell-Rubin likelihood ratio test; ALMR $=p$ value associated with the adjusted Lo-Mendell-Rubin likelihood ratio test; $\mathrm{BLRT}=p$ value associated with the bootstrap likelihood ratio test.

The AIC, BIC, and ABIC values failed to reach a minimum, and the LMR, ALMR and BLRT remained statistically significant $(p<.05)$. Since these tests are all tests of statistical significance, determining the optimal number of profiles can be influenced by sample size (Marsh et al., 2009), and indicators may likely improve without reaching a minimum (Howard et al., 2016). An examination of the plots indicated that adding a fifth profile resulted in the addition of a qualitatively and quantitatively different profile (i.e., profile with high scores on all variables), compared to the model with four profiles, whereas adding a sixth profile did not add anything theoretically meaningful (i.e., the profile parallels the fifth profile). Therefore, the more parsimonious five-profile model was preferred. The elbow plot in Figure 1 (below) supports the additional gain in fit between the fourth and fifth profile, illustrating a plateau has not been reached after the fourth profile.

The five-profile solution is also theoretically interpretable and yields adequate profiling the posterior class membership probabilities were above .93 (exceeding .70), and the entropy value (.95) was also high (exceeding .80). As displayed in Table 2 and Figure 2 (below), five profiles differing on both the burnout and engagement variables could be identified. Therefore, Hypothesis 1 is accepted.

Profile 1 (Burned-out) scored high on all burnout variables (especially on mental distance) and low to very low on the engagement variables (especially on dedication). They constituted $7.79 \%$ of the sample. Profile 2 (Risky) scored moderately high on burnout, but moderately low on engagement. They constituted $27.80 \%$ of the sample. Profile 3 (Stars) were the opposite of the risky profile with moderately low scores on burnout but moderately high to high scores on engagement (especially on dedication). They constituted $23.96 \%$ of the sample. Profile 4 (Moderately balanced) scored moderately on both burnout and engagement. They constituted $36.01 \%$ of the sample. Profile 5 (Workaholic) scored moderately high to high on all variables (especially dedication and absorption). They constituted $4.43 \%$ of the sample. 
Figure 1. Elbow plot for the information criteria

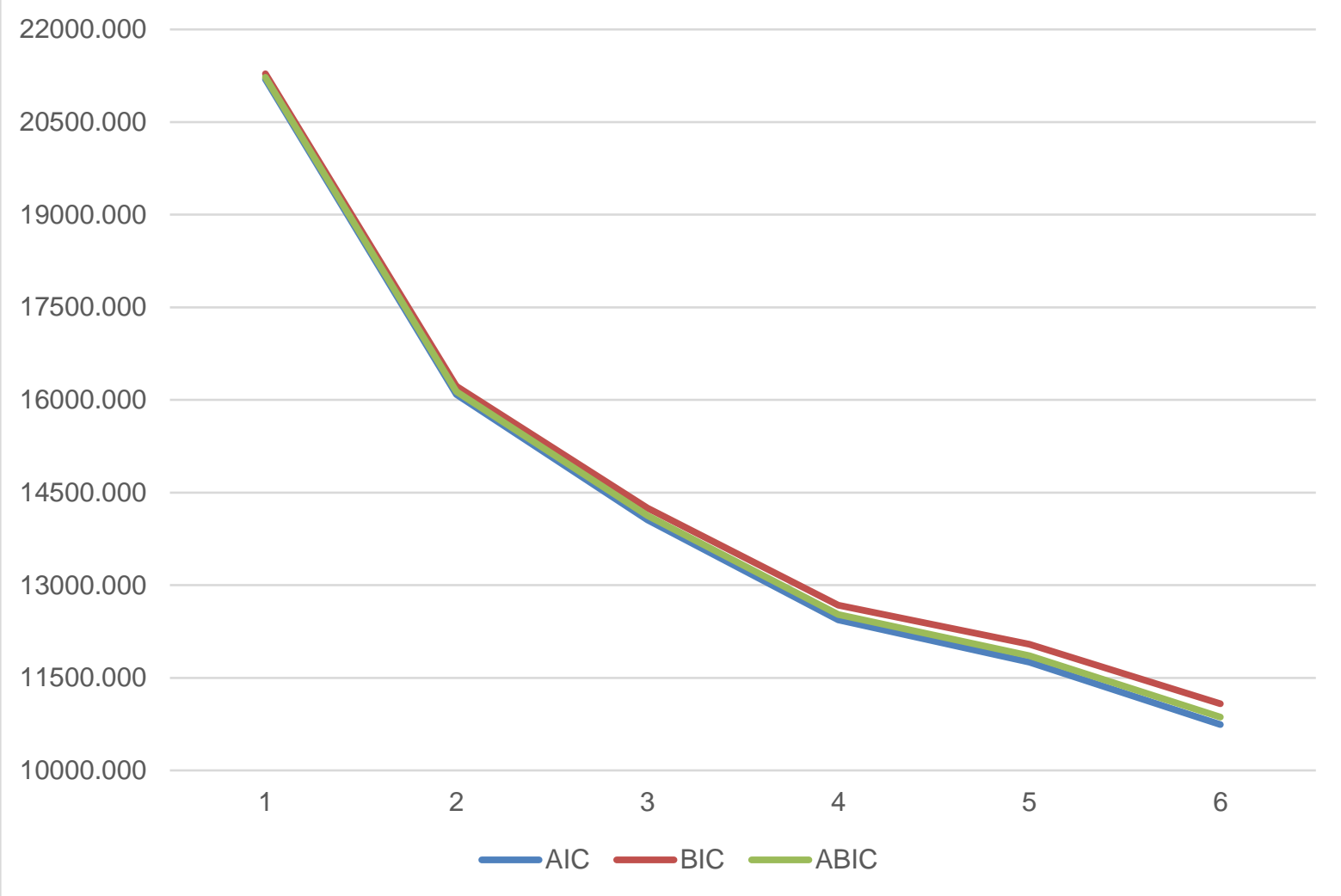

Table 2. Mean level differences for the burnout-engagement types

\begin{tabular}{|c|c|c|c|c|c|}
\hline & $\begin{array}{l}\text { Burned- } \\
\text { out }\end{array}$ & Risky & Stars & $\begin{array}{l}\text { Moderately } \\
\text { Balanced }\end{array}$ & Workaholic \\
\hline \multicolumn{6}{|c|}{ Burnout and Engagement Variables } \\
\hline BATEX & $1.07^{\mathrm{a}}$ & $0.56^{\mathrm{b}}$ & $-0.75^{\mathrm{d}}$ & $-0.24^{\mathrm{c}}$ & $0.63^{b}$ \\
\hline BATMD & $1.15^{\mathrm{a}}$ & $0.51^{\mathrm{b}}$ & $-0.65^{\mathrm{d}}$ & $-0.30^{c}$ & $0.71^{\mathrm{b}}$ \\
\hline BATCI & $0.98^{\mathrm{a}}$ & $0.59^{\mathrm{b}}$ & $-0.77^{\mathrm{d}}$ & $-0.22^{c}$ & $0.53^{b}$ \\
\hline BATEI & $0.86^{\mathrm{a}}$ & $0.44^{\mathrm{b}}$ & $-0.58^{\mathrm{d}}$ & $-0.21^{c}$ & $0.56^{b}$ \\
\hline BAT & $1.01^{\mathrm{a}}$ & $0.52^{\mathrm{b}}$ & $-0.69^{d}$ & $-0.22^{c}$ & $0.49^{b}$ \\
\hline VIGOR & $-1.28^{\mathrm{d}}$ & $-0.44^{c}$ & $0.69^{a}$ & $0.09^{b}$ & $0.61^{\mathrm{a}}$ \\
\hline DEDI & $-2.11^{e}$ & $-0.72^{\mathrm{d}}$ & $1.11^{\mathrm{a}}$ & $0.15^{\mathrm{c}}$ & $0.97 \mathrm{~b}$ \\
\hline ABSORP & $-1.71^{\mathrm{d}}$ & $-0.56^{c}$ & $0.90^{\mathrm{a}}$ & $0.09^{b}$ & $0.89^{a}$ \\
\hline ENGAGE & $-1.27 \mathrm{e}$ & $-0.43^{d}$ & $0.68^{a}$ & $0.09^{c}$ & $0.58^{\mathrm{b}}$ \\
\hline \multicolumn{6}{|l|}{ Correlates } \\
\hline $\begin{array}{l}\text { Psychological } \\
\text { distress }\end{array}$ & $0.57^{\mathrm{a}}$ & $0.40^{\mathrm{bc}}$ & $-0.46^{e}$ & $-0.15^{d}$ & $0.39 \mathrm{ac}$ \\
\hline Commitment & $-1.21^{\mathrm{e}}$ & $-0.45^{\mathrm{d}}$ & $0.65^{\mathrm{a}}$ & $0.11^{\mathrm{c}}$ & $0.39^{\mathrm{b}}$ \\
\hline $\begin{array}{l}\text { Turnover } \\
\text { intention }\end{array}$ & $1.26^{\mathrm{a}}$ & $0.61^{b}$ & $-0.75^{e}$ & $-0.24^{\mathrm{d}}$ & $0.26^{c}$ \\
\hline
\end{tabular}




\section{Figure 2. Burnout-engagement profiles}

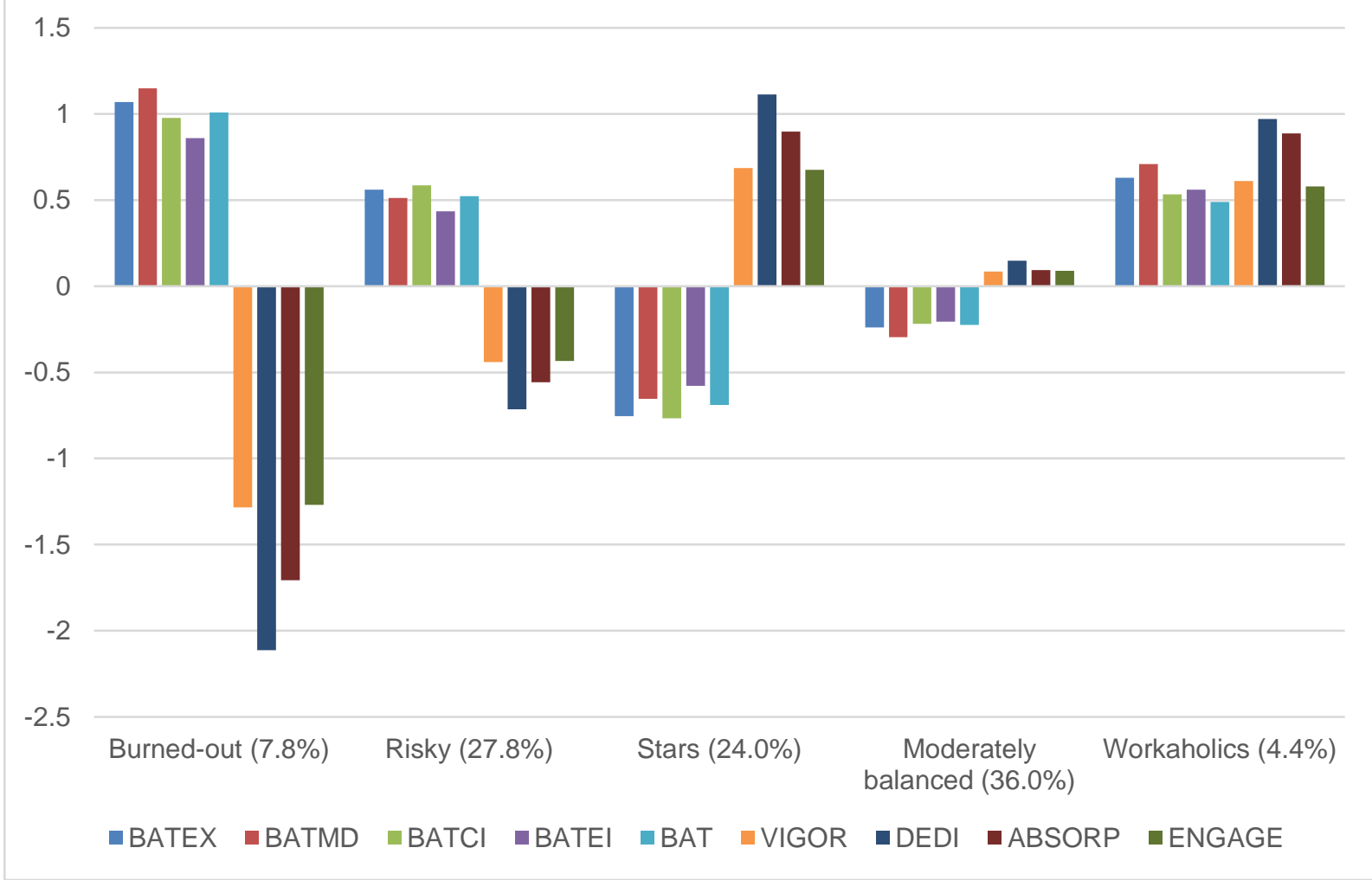

Note. BATEX = BAT Exhaustion; BATMD = BAT Mental Distance; BATCI = BAT Cognitive Impairment; BATEI = BAT Emotional Impairment; VIGOR = Vigor; DEDI = Dedication; ABSORP = Absorption; ENGAGE = Engagement.

Mean-level factor score differences were examined between the five types of burnoutengagement types regarding the burnout and engagement variables (see Table 2, above). The Burned-out profiles scored the highest on all the burnout variables, followed by the Risky and Workaholics (with equal levels), the Moderately balanced, with the Stars reporting the lowest levels of burnout. For engagement, the Stars reported higher levels on all engagement variables when compared to the Moderately balanced, the Risky, and the Burned-out (who reported the lowest levels). The Stars reported higher dedication and overall engagement levels than the Workaholics, but these two groups reported equal levels of vigor and absorption.

Post hoc analysis ${ }^{2}$ (i.e., cross-tabulation) was used to determine whether an association existed between sex and the burnout-engagement profiles. Pearson's chi-square $\left(\chi^{2}\right)$ test was employed to determine whether these associations between the categorical variables were significant. Cramer's V provided a measure of the strength of the association between the categorical variables (Field, 2018). Cohen's (1988) guidelines were used to determine the magnitude of the practical effect sizes: small (.10), medium (.30), and large (.50). As shown in Table 3 (below), the results indicated a significant association (of small effect) between sex and the burnout-engagement profiles. Results showed more females in the Burned-out and Risky groups, whereas the Stars group contained slightly more males (contrary to the expected counts).

\footnotetext{
${ }^{2}$ Post hoc analysis was performed based on a reviewer's recommendation as biological sex has been shown to be an important covariate in burnout literature.
} 
Table 3. Sex Associations with Profiles

\begin{tabular}{lllllll}
\hline & $\begin{array}{l}\mathbf{n} \\
\mathbf{( \% )}\end{array}$ & $\begin{array}{l}\text { Burned- } \\
\text { out } \\
\text { (expected } \\
\text { counts) }\end{array}$ & $\begin{array}{l}\text { Risky } \\
\text { (expected } \\
\text { counts) }\end{array}$ & $\begin{array}{l}\text { Stars } \\
\text { (expected } \\
\text { counts) }\end{array}$ & $\begin{array}{l}\text { Moderately } \\
\text { Balanced } \\
\text { (expected } \\
\text { counts) }\end{array}$ & $\begin{array}{l}\text { Workaholic } \\
\text { (expected } \\
\text { counts) }\end{array}$ \\
\hline Female & 570 & 51 & 186 & 114 & 196 & 23 \\
& $(54.49)$ & $(44.10)$ & $(158.60)$ & $(137.30)$ & $(204.30)$ & $(25.60)$ \\
Male & 476 & 30 & 105 & 138 & 179 & 24 \\
& $(45.51)$ & $(36.90)$ & $(132.40)$ & $(114.70)$ & $(170.70)$ & $(21.40)$ \\
$\chi^{2}(d f)$ & $22.81(4)^{*}$ & & & & & \\
Cramer's V & 0.15 & & & & &
\end{tabular}

Notes. $\mathrm{d} f=$ degrees of freedom; ${ }^{*} p<.001$

\subsection{Psychological Distress, Affective Organizational Commitment, and Turnover Intention as Correlates} of Profile Membership

A measurement model was specified for the correlates. Psychological distress, commitment, and turnover intention were specified as three correlated unidimensional variables. The model fitted the data acceptably $\left(\chi^{2}=721.13, \mathrm{~d} f=149, p<.001\right.$; RMSEA $=.07[.068, .079], p<.001 ; \mathrm{CFI}=.90$; $\mathrm{TLI}=.89 ; \mathrm{SRMR}=.05)$. Mean-level factor score differences were examined between the five types of burnout-engagement types regarding psychological distress, commitment, and turnover intention. As displayed in Table 2 and Figure 3, significant differences are reported between the different profiles, supporting the construct validity of the profiles.

Figure 3. Psychological distress, affective organizational commitment, and turnover intention as a function of profile membership

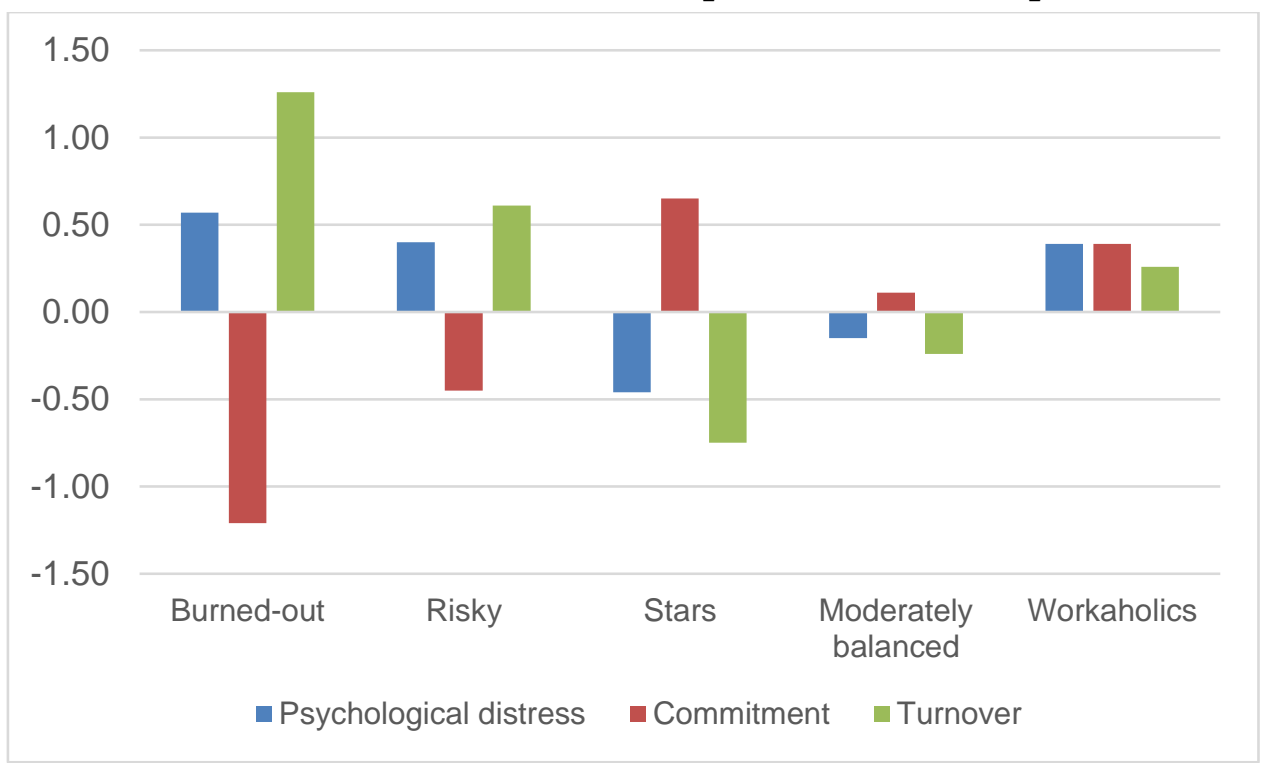

The Burned-out reported the higher levels of psychological distress than the Risky. Still, both reported higher levels than the Moderately balanced who also reported higher levels of psychological distress than the Stars. The Burned-out and the Workaholics reported equal levels of psychological distress. Therefore, Hypotheses 2a was accepted as profiles with high(er) levels of burnout and low(er) levels of engagement are less adaptive profiles with higher levels of distress compared to those with low(er) levels of burnout and high(er) levels of engagement. 
Those with high levels of both burnout and engagement will also reported high levels of distress, as expected.

The Stars reported the highest levels of commitment, followed by the Workaholics, the Moderately balanced, and the Risky, with the lowest levels reported by the Burned-out. Therefore, Hypotheses $2 \mathrm{~b}$ was accepted as profiles with high(er) levels of burnout and low(er) levels of engagement are less adaptive profiles with lower levels of affective commitment compared to those with low(er) levels of burnout and high(er) levels of engagement. Those with high levels of both burnout and engagement also had high levels of affective commitment, as expected.

The Burned-out reported the highest levels of turnover intention, followed by the Risky, the Workaholics, and the Moderately balanced, with the lowest levels reported by the Stars. Therefore, Hypotheses 2c was accepted as profiles with high(er) levels of burnout and low(er) levels of engagement are less adaptive profiles with higher levels of turnover intentions compared to those with low(er) levels of burnout and high(er) levels of engagement. Those with high levels of both burnout and engagement also have high levels of turnover intentions, as expected.

\section{Discussion}

Interventions aimed at enhancing individuals' work-related wellbeing of individuals are imperative given the direct consequences of COVID-19 (International Labor Organization, 2021) and its indirect effects that resulted in changes in the work environment (De Klerk et al., 2021; Koekemoer et al., 2021). Identifying work-related wellbeing profiles enables organizations to tailor their interventions for different groups of employees, enhancing the effectiveness of these interventions. Therefore, the current study aimed to identify such profiles among a sample of employees in a non-WEIRD context. The study also aimed to examine the implications of profile membership for employee affect and cognition to complement the validity of the profiles.

The results indicated that five profiles exist: Moderately balanced (36\%), Risky (28\%), Stars (24\%), Burned-out (8\%) and Workaholics (4\%). The configurations of these profiles overlap to a great extent with the profiles identified by Moeller et al. (2018). The prevalence of these profiles also differed somewhat from Moeller et al.'s (2018): less engaged (or Stars) and Workaholic profiles but more Burned-out profiles. The JD-R theory supports the buffering effect of job resources in counteracting the health impairment process transpiring from job demands (Bakker \& Demerouti, 2017). Non-WEIRD (or developing) countries generally have less access to resources (Janik \& Rothmann, 2015), potentially increasing the prevalence of Burned-out profiles in this context. However, the prevalence of the engaged versus workaholics profiles overlaps with the findings of Innanen et al. (2014): more engaged (or Stars) profiles than Workaholic profiles.

Post hoc analysis for biological sex showed that females were slightly more prevalent in the Burned-out and Risky profiles. In past research, female participants have shown a tendency to score higher on burnout than males (e.g., Bakker et al., 2010; Thrush et al., 2019) and in South Africa (De Beer et al., 2016). However, it has been speculated that males may under-report burnout (Agrawal et al., 2020) and other mental health issues (e.g., Sigmon et al., 2005).

Insofar the implications of these profiles are concerned, Burned-out individuals are most in need of assistance as they have high levels of distress. They are the least committed, and they are most likely to leave the organization. Similarly, the Risky is at risk because they are also distressed. They show little commitment to the organization and want to leave (although they are better on all indicators than the Burned-out). The Moderately balanced are perhaps less concerning as they are less distressed, more committed to the organization, and more inclined to stay with the organization than their Burned-out and Risky counterparts. The Stars have the 
lowest levels of distress, are the least likely to leave the organization, and are the most committed to the organization. These findings are in line with previous research that reported more favorable associations between profiles with low(er) levels of burnout and high(er) levels of engagement and affective and cognitive outcomes (Abós et al., 2019; Innanen et al., 2014; Moeller et al., 2018). Supporting the JD-R theory (Bakker \& Demerouti, 2017), the less adaptive profiles (i.e., Burned-out and Risky) experience a health impairment process in which their psychological functioning is impaired. The more adaptive profiles (i.e., Stars and Moderately balanced) experience a motivational process that enhances their psychological functioning. The former is also less attached to the organization due to an impaired identification (Knoll et al., 2019; Meyer et al., 2006). The Workaholics are Pandora's boxes; they are very engaged and committed, but they experience similar distress to the Burned-out and are at risk of leaving the organization. Previous research demonstrated that these individuals have difficulty detaching from work (Innanen et al., 2014) which may explain their high levels of psychological distress and commitment. They strongly identify with the organization, but they want to leave because of the price they pay (i.e., elevated psychological distress). The 'price they pay' may manifest as job dissatisfaction (with a resultant desire to leave) and is in line with other research that demonstrated the negative association between workaholism and job satisfaction in a nonWEIRD context (Valenzuela \& Díaz, 2010). Consequently, these employees may still perform above average, and managers might be tempted not to intervene as they do not want to interrupt the status quo. However, these employees are at similar risk to their Burned-out counterparts.

In conclusion, the current study extends the scientific conversation on burnout-engagement profiles in several ways. In support of the circumplex model of subjective wellbeing (Bakker \& Oerlemans, 2011), the current findings illustrated that burnout and engagement could be interpreted as two opposites of the continuum (i.e., negatively correlated). But they can also cluster together in the same direction (i.e., positive correlation) within the individual. Thus, combining the components (rather than the components in isolation) determines whether employee outcomes will be positive or negative. Without a person-centered approach, the 'darker side' of engagement (as becomes evident in the Workaholic profile) may not be visible (Moeller et al., 2018).

Furthermore, burnout seems to co-vary quite strongly in all the profiles when considering the total and specific components, whereas the opposite seems true for engagement. For engagement, it is evident that the (lack of) dedication drives (the lack of) engagement, especially in the Burned-out profile. Consequently, these results indicate that it was worthwhile to model engagement as a global construct with separate components rather than a unidimensional construct.

Although the findings of the current study support general trends (in both the configurations and prevalence of profiles), slight differences were observed. Apart from the differences in the prevalence of some profiles discussed earlier, the current sample did not identify any apathetic profiles (i.e., profiles with low scores on burnout and engagement). These differences may allude to the importance of context when investigating wellbeing profiles. One may observe core profiles that will be replicable across different contexts, but profiles can emerge that are context specific.

\section{Limitations and recommendations for future research}

This study was not without limitations. The first limitation was that the data was cross-sectional and did not allow for analyzing transitions between classes as would be possible with longitudinal data. Future researchers should consider longitudinal designs and implement 
analytical techniques such as latent transition analysis (Wang \& Wang, 2020). The longitudinal analysis will also enable researchers to determine cause-and-effect between profile membership and employee outcomes which were not possible in the current study. Secondly, even though our sample was quite large and exceed the recommendations for the minimum sample size $(n=500)$ for LPA (Tein et al., 2013), we cannot discount the possibility that a larger group of participants would not have yielded an additional group (e.g., apathetic) which might exist in the population. Thirdly, recent research has shown that burnout and depression have significant overlaps, especially the exhaustion component, and that burnout is likely a syndrome on the depressive spectrum (Bianchi et al., 2021). Therefore, in future profile analyses, including a measure of depression might be an interesting addition. Lastly, our sample was non-probability in nature, and representative samples in organizational research in South Africa are almost nonexistent for many reasons (e.g., lack of sampling frames, lack of accurate statistics about representation in the formal sector, and a lack of consensus on which variables to use to ensure fair representation). Even so, the generalization of our results should not be made carelessly.

\section{Practical implications}

Based on the findings of this study, a differentiated approach to interventions is recommended. For example, most of the sample falls into more adaptive profiles (i.e., Moderately balanced and Stars). These individuals may benefit more from identifying 'what works well', and these elements can be used to optimize wellbeing (and consequently affective and cognitive outcomes). It may be more worthwhile for the Risky to focus on preventative measures to prevent their transitioning into Burned-out employees. In contrast, the Burned-out and Workaholics may benefit more from remedially orientated measures to facilitate recovery. The current study did not investigate the antecedents of profile membership. However, well-known organizations (e.g., Gallup) and academics (Bakker, Demerouti, and Schaufeli) have identified the precursors to burnout and engagement. For example, the JD-R theory stipulates that an excess of hindrance demands (e.g., conflict and role ambiguity) and the absence of challenge demands (e.g., responsibility) and resources (e.g., managerial and collegial support) in the workplace are antecedents of burnout and engagement (Bakker \& Demerouti, 2017). This notion overlaps with Gallup's (2020) identification of the top five causes of burnout: "unfair treatment, unmanageable workload, unclear communication from managers, lack of manager support, and unreasonable time pressure" (p. 7). Regardless of the focus (i.e., optimization, proactivity, or remediation) or the specific causes (i.e., demands or resources), a top-down and bottom-up approach to intervention is recommended (see Van Wingerden \& Van der Vaart, 2019 for more detail). Top-down approaches such as managerial support can include supporting employees' needs for autonomy, competence, and relatedness as advocated for by the self-determination theory (Ryan \& Deci, 2017). Such supportive practices include shared decision-making (autonomy support), uplifting feedback (competence support), and demonstrating interest (relatedness support) (Van der Vaart \& Van den Broeck, 2019). Bottom-up approaches such as job crafting (Zhang \& Parker, 2019) or need crafting (Laporte et al., 2021) can include asking for clarity or doing more of what you are good at. Crafting can create meaning (Zhang \& Parker, 2019), which enhances wellbeing (Gallup, 2020). Alternatively, counselling and effort-recovery strategies (e.g., sleep, exercise, setting boundaries) may be beneficial. Ultimately, the organization should take a strategic approach to wellbeing, entrenching it into the organizational culture and every step of the employee experience cycle (i.e., attraction, hiring, onboarding, engagement, performance, development, and departure) (Gallup, 2020). 


\section{Conclusion}

Even though burnout and engagement can be considered opposite ends on a continuum, the profiles identified in the current study show that individuals can also have scores on all components of burnout and engagement, which can be in opposite directions or even in the same direction. The results also illustrate that these combinations matter for affective and cognitive employee outcomes, outcomes that matter for optimal and productive work.

\section{Conflict of interest statement}

The authors declare no conflict of interest in the publication of this article. The research funder had no role in the study's design nor in the collection, analyses, or interpretation of the data; in the writing of the manuscript; or in the decision to publish the results.

\section{Funding}

This study formed part of a project that was supported by the National Research Foundation (NRF, South Africa) under reference number CSRP170523232041 (Grant No: 112106). The views and opinions expressed are those of the researchers and do not reflect the opinions or views of the NRF.

\section{Data availability statement}

The associated analyses and data for the current study can be requested from the authors. All reasonable requests will be considered.

\section{Authors}

Leoni van der Vaart

North-West University

12772356@g.nwu.ac.za

Leon T. de Beer

North-West University

leondb@gmail.com

\section{Authors' Contributions}

Van der Vaart and De Beer conceptualized the study. Van der Vaart took the lead in the literature review, the writing of the manuscript, and the statistical analyses for the latent profiles. De Beer acted as an additional writer, reviewed the manuscript, performed the data management for use in the analyses, and assisted with the initial modelling of the data before the profile analyses.

\section{Publishing Timeline}

Received 27 July 2021

Revised version received 30 August 2021

Accepted 22 September 2021

Published 30 September 2021

\section{References}

Abós, Á., Sevil-Serrano, J., Haerens, L., Aelterman, N., \& García-González, L. (2019). Towards a more refined understanding of the interplay between burnout and engagement among secondary school teachers: A person-centered perspective. Learning and Individual Differences, 72, 69-79. https://doi.org/10.1016/j.lindif.2019.04.008 
Allen, N. J., \& Meyer, J. P. (1996). Affective, continuance and normative commitment to the organization: An examination of construct validity. Journal of Vocational Behavior, 49, 252-276. https://doi.org/10.1006/jvbe.1996.0043

Allen, N. J., \& Meyer, J. P. (1990). The measurement and antecedents of affective, continuance and normative commitment to the organization. Journal of Occupational Psychology, 63(1), 1-18. https://doi.org/10.1111/j.2044-8325.1990.tb00506.x

Agrawal, V., Plantinga, L., Abdel-Kader, K., Pivert, K., Provenzano, A., Soman, S., Choi, M. J., \& Jaar, B. G. (2020). Burnout and emotional well-being among nephrology fellows: A national online survey. Journal of the American Society of Nephrology, 31(4), 675-685. https://doi.org/10.1681/asn.2019070715

Asparouhov, T., \& Muthén, B. (2015). Auxiliary variables in mixture modeling: Using the BCH method in Mplus to estimate a distal outcome model and an arbitrary secondary model. Retrieved from https://www.statmodel.com/download/asparouhov_muthen_2014.pdf

Bakk, Z., \& Vermunt, J. K. (2016). Robustness of stepwise latent class modeling with continuous distal outcomes. Structural Modeling: A Multidisciplinary Journal, 23(1), 20-31. https://doi.org/10.1080/10705511.2014.955104

Bakker, A. B., \& Demerouti, E. (2017). Job demands-resources theory: Taking stock and looking forward. Journal of Occupational Health Psychology, 22, 273-285. https://doi.org/10.1037/ocp0000056

Bakker, A. B., Demerouti, E., \& Sanz-Vergel, A. I. (2014). Burnout and engagement: The JD-R approach. Annual Review of Organizational Psychology and Organizational Behaviour, 1, 389-411. https://doi.org/10.1146/annurev-orgpsych-031413-091235

Bakker, A. B., Demerouti, E., \& Schaufeli, W. B. (2002). Validation of the Maslach burnout inventorygeneral survey: An internet study. Anxiety, Stress \& Coping, 15(3), 245-260. https://doi.org/10.1080/1061580021000020716

Bakker, A. B., \& Oerlemans, W. G. M. (2011). Subjective well-being at work in organizations. In K.Cameron, \& G. Spreitzer (Eds.), Handbook of positive organizational scholarship (pp. 178-189). Oxford University Press.

Bianchi, R., Verkuilen, J., Schonfeld, I. S., Hakanen, J. J., Jansson-Fröjmark, M., Manzano-García, G., ... \& Meier, L. L. (2021). Is burnout a depressive condition? A 14-sample meta-analytic and bifactor analytic study. Clinical Psychological Science, Article 2167702620979597. https://doi.org/10.1177/2167702620979597

Clark, S. L. (2010). Mixture modeling with behavioral data (UMI No. 3405665) [Doctoral dissertation, University of California]. ProQuest Dissertations and Theses Global.

Coetzee, M., \& van Dyk, J. (2018). Workplace bullying and turnover intention: Exploring work engagement as potential mediator. Psychological Reports, 121(2), 375-392. https://doi.org/10.1177/0033294117725073

Cohen J. W. (1988). Statistical power analysis for the behavioral sciences (2nd ed.). Lawrence Erlbaum Associates.

De Beer, L. T. (2021). Is there utility in specifying professional efficacy as an outcome of burnout in the employee health impairment process. International Journal of Environmental Research and Public Health, 18, Article 6255. https://doi.org/10.3390/ijerph18126255

De Beer, L.T., \& Bianchi, R. (2019). Confirmatory factor analysis of the Maslach Burnout Inventory: A Bayesian structural equation modeling approach. European Journal of Psychological Assessment, 35(2), 217-224. https://doi.org/10.1027/1015-5759/a000392

De Beer, L. T., Pienaar, J., \& Rothmann Jr, S. (2016). Work overload, burnout, and psychological illhealth symptoms: a three-wave mediation model of the employee health impairment process. Anxiety, Stress, E Coping, 29(4), 387-399. https://doi.org/10.1080/10615806.2015.1061123

De Beer, L. T., Schaufeli, W. B., De Witte, H. Hakanen, J. J., Shimazu, A., Glaser, J., Seubert, C., Bosak, J., Sinval, J., Rudnev, M. (2020). Measurement invariance of the Burnout Assessment Tool (BAT) across seven cross-national representative samples. International Journal of Environmental Research and Public Health, 17, Article 5604. https://doi.org/10.3390/ijerph17155604 
Decuypere, A., \& Schaufeli, W. B. (2020). Leadership and work engagement: Exploring explanatory mechanisms. German Journal of Human Resource Management, 34(1), 69-95. https://doi.org/10.1177/2397002219892197

De Klerk, J. J., Joubert, M., Mosca, H. F. (2021). Is working from home the new workplace panacea? Lessons from the COVID-19 pandemic for the future world of work. SA Journal of Industrial Psychology, 47, Article 1883. https://doi.org/10.4102/sajip.v47i0.1883

Field A. (2018). Discovering statistics using IBM SPSS statistics (5th ed.). Sage.

Gallup. (2020). Gallup's perspective on employee burnout: Causes and cures. https://www.gallup.com/workplace/282659/employee-burnout-perspective-paper.aspx

Gillet, N., Morin, A. J. S., Colombat, P., Ndiaye, A., \& Fouquereau, E. (2021). Burnout profiles: Dimensionality, replicability, and associations with predictors and outcomes. Current Psychology. Advance online publication. https://doi.org/10.1007/s12144-021-01807-3

Giorgi, G., Lecca, L. I., Alessio, F., Finstad, G. L., Bondanini, G., Lulli, L. G., Arcangeli, G., \& Mucci, N. (2020). COVID-19-related mental health effects in the workplace: A narrative review. International Journal of Environmental Research and Public Health, 17(21), Article 7857. https://doi.org/10.3390/ijerph17217857

Guo, J., Qiu, Y., \& Gan, Y. (2020). Workplace incivility and work engagement: The chain mediating effects of perceived insider status, affective organizational commitment and organizational identification. Current Psychology. Advance online publication. https://doi.org/10.1007/s12144-02000699-z

Hellgren, J., Sjöberg, A. \& Sverke, M. (1997). Intention to quit: Effects of job satisfaction and job perceptions. In F. Avallone, J. Arnold \& K. de Witte (Eds.), Feelings work in Europe (pp. 415-423). Guerini.

Howard, J., Gagné, M., Morin, A. J. S., \& Van den Broeck, A. (2016). Motivation profiles at work: A selfdetermination theory approach. Journal of Vocational Behavior, 95-96, 74-89. https://doi.org/10.1016/j.jvb.2016.07.004

Innanen, H., Tolvanen, A., Salmela-Aro, K. (2014). Burnout, work engagement and workaholism among highly educated employees: Profiles, antecedents and outcomes. Burnout Research, 1, 38-49. https://doi.org/10.1016/j.burn.2014.04.001

International Labor Organization. (2021). COVID-19 and the world of work. https://www.ilo.org/global/topics/coronavirus/lang--en/index.htm

Janik, M., \& Rothmann, S. (2015). Meaningful work and secondary school teachers' intention to leave. South African Journal of Education, 35(2), 1-13. https://org.doi/10.15700/saje.v35n2a1008

Kline, R. B. (2016). Principles and practice of structural equation modeling (4th ed.). Guilford Publications.

Knoll, M., Hall, R. J., \& Weigelt, O. (2019). A longitudinal study of the relationships between four differentially motivated forms of employee silence and burnout. Journal of Occupational Health Psychology, 24, 572-589. https://doi.org/10.1037/ocp0000143

Koekemoer, L., De Beer, L.T., Govender, K., Brouwers, M. (2021). Leadership behaviour, team effectiveness, technological flexibility, work engagement and performance during COVID-19 lockdown: An exploratory study. SA Journal of Industrial Psychology, 47, Article 1829. https://doi.org/10.4102/sajip.v47i0.1829

Laporte, N., Soenens, B., Brenning, K., \& Vansteenkiste, M. (2021). Adolescents as active managers of their own psychological needs: The role of psychological need crafting in adolescents' mental health. Journal of Adolescence, 88(1), 67-83. https://doi.org/10.1016/j.adolescence.2021.02.004

Lubke, G. H., \& Neale, M. C. (2006). Distinguishing between latent classes and continuous factors: Resolution by maximum likelihood. Multivariate Behavioral Research, 41(4), 499-532. https://doi.org/10.1207/s15327906mbr4104_4

Marsh, H. W., Lüdtke, O., Trautwein, U., \& Morin, A. J. S. (2009). Classical latent profile analysis of academic self-concept dimensions: Synergy of person- and variable-centered approaches to theoretical models of self-concept. Structural Equation Modeling, 16, 191-225.

https://doi.org/10.1080/10705510902751010 
Meyer, J. P., Becker, T. E., \& Van Dick, R. (2006). Social identities and commitment at work: Toward an integrative model. Journal of Organizational Behavior, 27, 665-683. https://doi.org/10.1002/job.383

Meyer, J. P., \& Morin, A. J. (2016). A person-centered approach to commitment research: Theory, research, and methodology. Journal of Organizational Behavior, 37(4), 584-612. https://doi.org/10.1002/job.2085

Moeller, J., Ivcevic, Z., White, A. E., Menges, J. I., \& Brackett, M. A. (2018). Highly engaged but burned out: Intra-individual profiles in the US workforce. Career Development International, 23(1), 86-105. https://doi.org/10.1108/CDI-12-2016-0215

Morin, A. J. S., Bujacz, A., \& Gagné, M. (2018). Person-centered methodologies in the organizational sciences: Introduction to the feature topic. Organizational Research Methods, 21(4), 803-813. https://doi.org/10.1177/1094428118773856

Muthén, B., \& Muthén, L. K. (2000). Integrating person-centered and variable-centered analyses: Growth mixture modeling with latent trajectory classes. Alcoholism: Clinical and Experimental Research, 24(6), 882-891. https://doi.org/10.1111/j.1530-0277.2000.tb02070.x

Muthén, L. K., \& Muthén, B. O. (1998-2021). Mplus user's guide (8th ed.). Muthén \& Muthén.

Nagin, D. (2005). Group-based modeling of development. Harvard University Press.

Nylund, K. L., Asparouhov, T., \& Muthén, B. O. (2007). Deciding on the number of classes in latent class analysis and growth mixture modeling: A Monte Carlo simulation study. Structural Equation Modeling: A Multidisciplinary Journal, 14, 535-569. https://doi.org/10.1080/10705510701575396

Ryan, R. M., \& Deci, E. L. (2017). Self-determination theory: Basic psychological needs in motivation, development, and wellness. Guilford Press.

Salmela-Aro, K., Hietajärvi, L., \& Lonka, K. (2019). Work burnout and engagement profiles among teachers. Frontiers in Psychology, 10, Article 2254. https://doi.org/10.3389/fpsyg.2019.02254

Sarisik, M., Bogan, E., Zengin, B., \& Dedeoglu, B. B. (2019). The impact of burnout on organizational commitment: A study of public sector employees in Turkey. Journal of Global Business Insights, 4(2), 106-118. https://www.doi.org/10.5038/2640-6489.4.2.1066

Schaufeli, W. B. (2017a). Work engagement in Europe: Relations with national economy, governance, and culture. https://www.wilmarschaufeli.nl/publications/Schaufeli/491a.pdf

Schaufeli, W. B. (2017b). Applying the job demands-resources model. Organizational Dynamics, 2(46), 120-132. http://dx.doi.org/10.1016/j.orgdyn.2017.04.008

Schaufeli, W. B., \& Bakker, A. B. (2004). Job demands, job resources, and their relationship with burnout and engagement: A multi-sample study. Journal of Organizational Behavior, 25(3), $293-315$. https://www.doi.org/10.1002/job.248

Schaufeli, W. B., Bakker, A. B., \& Salanova, M. (2006). The measurement of work engagement with a short questionnaire. Educational and Psychological Measurement, 66(4), 701-716. https://doi.org/10.1177/0013164405282471

Schaufeli, W. B., Desart, S., \& De Witte, H. (2020). Burnout assessment tool (BAT) - Development, validity, and reliability. International Journal of Environmental Research and Public Health, 17, Article 9495. https://doi.org/10.3390/ijerph17249495

Schaufeli, W. B., \& Salanova, M. (2007). Efficacy or inefficacy, that's the question: Burnout and work engagement, and their relationships with efficacy beliefs. Anxiety, Stress, E Coping, 20(2), 177-196. https://doi.org/10.1080/10615800701217878

Shimazu, A., Schaufeli, W. B., Kubota, K., Watanabe, K., \& Kawakami, N. (2018). Is too much work engagement detrimental? Linear or curvilinear effects on mental health and job performance. PLoS One, 13(12), Article e0208684. https://doi.org/10.1371/journal.pone.0208684

Sigmon, S.T., Pells, J.J., Boulard, N.E., Whitcomb-Smith, S., Edenfield, T.M., Hermann, B.A., Lamattina, S.M., Schartel, J.G., \& Kubik, E. (2005). Gender differences in self-reports of depression: The response bias hypothesis revisited. Sex Roles, 53(5-6), 401-411. https://doi.org/401411.10.1007/s11199-005-6762-3

Tein, J., Coxe, S., \& Cham, H. Statistical power to detect the correct number of classes in latent profile analysis. Structural Equation Modeling: A Multidisciplinary Journal, 20(4), 640-657.

http://dx.doi.org/10.1080/10705511.2013.824781 
Tett, R. P., \& Meyer, J. P. (1993). Job satisfaction, organizational commitment, turnover intention, and turnover: Path analyses based on meta-analytic findings. Personnel Psychology, 46(2), 259-293. https://doi.org/10.1111/j.1744-6570.1993.tb00874.x

Tofighi, D., \& Enders, C. K. (2008). Identifying the correct number of classes in growth mixture models. In G. R. Hancock \& K. M. Samuelsen (Eds.), Advances in latent variable mixture models (pp. 317-341). Information Age Publishing.

Thrush, C. R., Guise, J. B., Gathright, M. M., Messias, E., Flynn, V., Belknap, T., Thapa, P. B., Williams, D. K., Nada, E. M., \& Clardy, J. A. (2019). A one-year institutional view of resident physician burnout. Academic Psychiatry, 43(4), 361-368. https://doi.org/10.1007/s40596-019-01043-9

Valenzuela, A. V., \& Díaz, E. M. (2010). Adicción al trabajo, satisfacción laboral y familiar en académicos de una universidad estatal chilena [Workaholism, work and family satisfaction in academics from a Chilean state university]. Salud E Sociedad, 1(3), 222-232. http://dx.doi.org/10.22199/S07187475.2010.0003.00006

Van der Vaart, L., \& Van den Broeck, A. (2019). Self-determination and positive psychology interventions: A extension of the positive activity model in the context of unemployment. In L.E. van Zyl \& S. Rothmann (Eds.), Theoretical approaches to multi-cultural positive psychological interventions (vol. 1, pp. 51-67). Springer.

Van Mol, M. M., Nijkamp, M. D., Bakker, J., Schaufeli, W. B., \& Kompanje, E. J. (2018). Counterbalancing work-related stress? Work engagement among intensive care professionals. Australian Critical Care, 31(4), 234-241. https://doi.org/10.1016/j.aucc.2017.05.001

Van Wingerden, J., \& Van der Vaart, L. (2019). The potential of job demands-resources interventions in organizations. In L. E. van Zyl \& S. Rothmann (Eds.), Theoretical approaches to multi-cultural positive psychological interventions (Vol. 1, pp. 97-114). Springer.

Vinueza-Solórzano, A. M., Portalanza-Chavarría, C. A., de Freitas, C. P., Schaufeli, W. B., De Witte, H., Hutz, C. S., \& Souza Vazquez, A. C. (2021). The Ecuadorian Version of the Burnout Assessment Tool (BAT): Adaptation and Validation. International Journal of Environmental Research and Public Health, 18(13), Article 7121. https://doi.org/10.3390/ijerph18137121

Wang, H., Jin, Y., Wang, D., Zhao, S., Sang, X., \& Yuan, B. (2020). Job satisfaction, burnout, and turnover intention among primary care providers in rural China: Results from structural equation modeling. BMC Family Practice, 21, Article 12. https://doi.org/10.1186/s12875-020-1083-8

Wang, J., \& Wang, X. (2020). Structural equation modeling: Applications using Mplus (2nd ed.). Wiley.

World Health Organization (2019). Burn-out an "occupational phenomenon": International Classification of Diseases. Retrieved from https://www.who.int/mental_health/evidence/burn-out/en/

Zhang, F., \& Parker, S. K. (2019). Reorienting job crafting research: A hierarchical structure of job crafting concepts and integrative review. Journal of Organizational Behavior, 40(2), 126-146. https://doi.org/10.1002/job.2332 